Check for updates

Cite this: Chem. Sci., 2019, 10, 3217

๑ All publication charges for this article have been paid for by the Royal Society of Chemistry

Received 3rd December 2018

Accepted 4th February 2019

DOI: $10.1039 /$ c8sc05390a

rsc.li/chemical-science

\section{Catalytic radical difluoromethoxylation of arenes and heteroarenes $\uparrow$}

\author{
Johnny W. Lee, (D) $\ddagger^{a}$ Weijia Zheng, (I) $\ddagger^{a}$ Cristian A. Morales-Rivera, ${ }^{b}$ Peng Liu (D) *b \\ and Ming-Yu Ngai (D) *a
}

Intermolecular $\mathrm{C}-\mathrm{H}$ difluoromethoxylation of (hetero)arenes remains a long-standing and unsolved problem in organic synthesis. Herein, we report the first catalytic protocol employing a redox-active difluoromethoxylating reagent $1 \mathrm{a}$ and photoredox catalysts for the direct $\mathrm{C}-\mathrm{H}$ difluoromethoxylation of (hetero)arenes. Our approach is operationally simple, proceeds at room temperature, and uses benchstable reagents. Its synthetic utility is highlighted by mild reaction conditions that tolerate a wide variety of functional groups and biorelevant molecules. Experimental and computational studies suggest single electron transfer (SET) from excited photoredox catalysts to 1a forming a neutral radical intermediate that liberates the $\mathrm{OCF}_{2} \mathrm{H}$ radical exclusively. Addition of this radical to (hetero)arenes gives difluoromethoxylated cyclohexadienyl radicals that are oxidized and deprotonated to afford the products of difluoromethoxylation.

\section{Introduction}

Modern drug discovery and development involves extensive fine-tuning of physicochemical properties of drug candidates. A common approach to control these properties involves incorporation of fluorine-containing functional groups such as the difluoromethoxy $\left(\mathrm{OCF}_{2} \mathrm{H}\right)$ group into drug candidates. ${ }^{1}$ The $\mathrm{OCF}_{2} \mathrm{H}$ moiety is a privileged functional group in medicinal chemistry because molecules bearing the $\mathrm{OCF}_{2} \mathrm{H}$ group have dynamic lipophilicity, where they can adjust their lipophilicity to adapt to the chemical environment via simple bond rotations. ${ }^{2}$ In addition, $\mathrm{OCF}_{2} \mathrm{H}$-containing aromatic compounds can have an orthogonal structural geometry that enriches molecular spatial complexity and provides additional binding affinity to active sites in a target. ${ }^{3}$ Thus, incorporation of the $\mathrm{OCF}_{2} \mathrm{H}$ group into organic molecules often enhances their therapeutic efficacy by increasing metabolic stability, improving cellular membrane permeability, and altering pharmacokinetic properties. ${ }^{3}$ As a result, the $\mathrm{OCF}_{2} \mathrm{H}$ group is prevalent among pharmaceuticals and agrochemicals such as Pantoprazole ${ }^{\circledR}$ (a proton-pump inhibitor that is one of the top 100 selling drugs), ${ }^{4}$ Roflumilast ${ }^{\circledR}$, Flucythrinate ${ }^{\circledR}$, and Diflumetorim ${ }^{\circledR}$ (Scheme 1a).

Even though numerous biologically active molecules have the $\mathrm{OCF}_{2} \mathrm{H}$ motif in an aromatic system, access to such

\footnotetext{
${ }^{a}$ Department of Chemistry, Institute of Chemical Biology and Drug Discovery, Stony Brook University, Stony Brook, NY 11794, USA. E-mail: ming-yu.ngai@stonybrook.edu ${ }^{b}$ Department of Chemistry, University of Pittsburgh, Pittsburgh, PA 15260, USA. E-mail: pengliu@pitt.edu

$\dagger$ Electronic supplementary information (ESI) available. See DOI: 10.1039/c8sc05390a

\$ These authors contributed equally to this work.
}

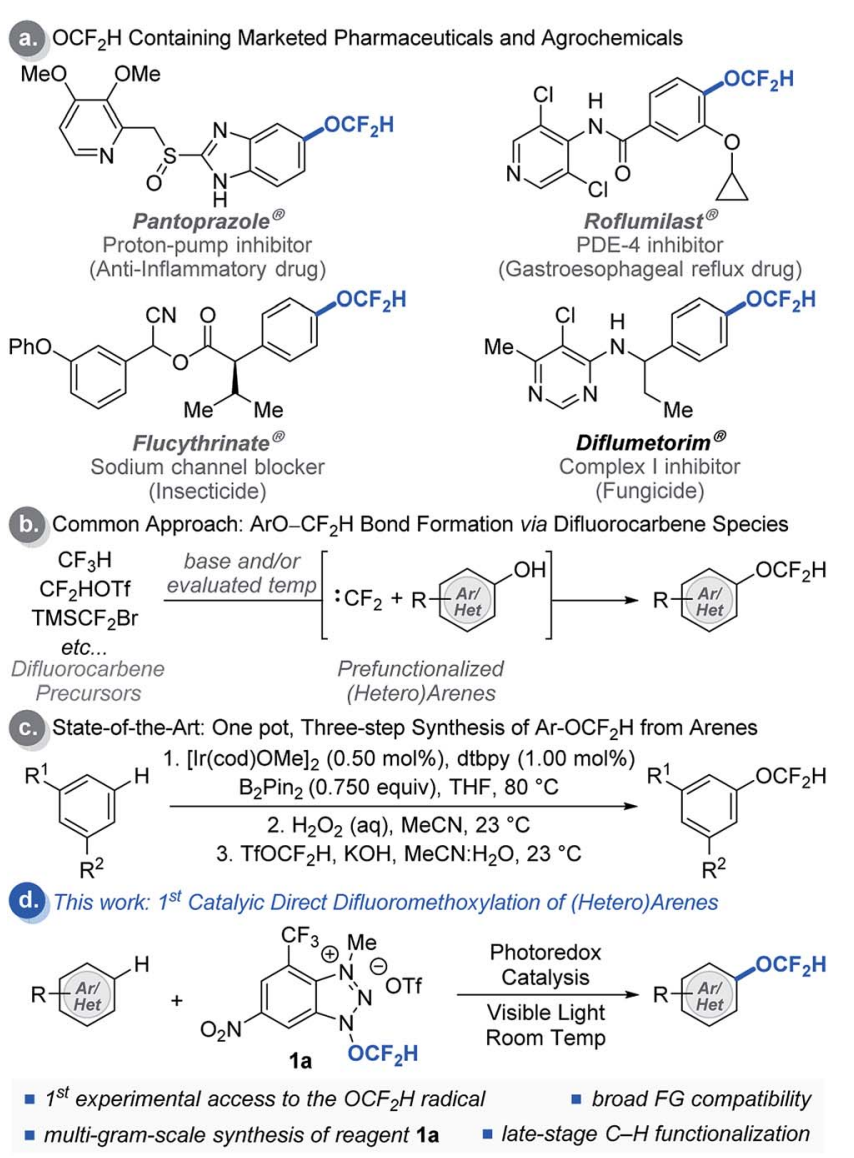

Scheme 1 Applications and strategies for the synthesis of difluoromethoxylated (hetero)arenes. 
analogues often requires the installation of the $\mathrm{OCF}_{2} \mathrm{H}$ group at an early stage of a multi-step synthetic sequence. The most common approach relies on $\mathrm{O}$-difluoromethylation of phenols using different difluorocarbene precursors under basic and/or evaluated temperature conditions (Scheme 1b). ${ }^{5}$ This strategy has facilitated the site-selective synthesis of aryl difluoromethyl ethers, but identification of the ideal position of the $\mathrm{OCF}_{2} \mathrm{H}$ substitution in a drug candidate still requires parallel and laborious multi-step syntheses from aryl precursors bearing activating or directing groups at various positions in an aromatic ring. Hartwig et al. recently developed an elegant onepot, three-step aryl $\mathrm{C}-\mathrm{H}$ difluoromethoxylation protocol involving (i) catalytic $\mathrm{C}-\mathrm{H}$ borylation of arenes, (ii) oxidation of the boronate esters, and (iii) difluoromethylation of phenols (Scheme 1c). ${ }^{5 h}$ Although this method has advanced the state-ofthe-art, a catalytic, direct intermolecular $\mathrm{C}-\mathrm{H}$ difluoromethoxylation of (hetero)arenes remains elusive.

As a part of our ongoing program to access and harness the reactivity of heteroatom radicals, ${ }^{6}$ we questioned whether a radical-mediated aromatic substitution using the $\mathrm{OCF}_{2} \mathrm{H}$ radical would allow direct introduction of the $\mathrm{OCF}_{2} \mathrm{H}$ group to a drug candidate generating multiple regioisomers in a single chemical operation. Such an approach is appealing because it obviates the need for laborious synthetic effort and the prefunctionalization of aromatic compounds. Moreover, the preparation and isolation of regioisomers would allow rapid assays of the biological activity of $\mathrm{OCF}_{2} \mathrm{H}$ analogues, a feature which would be particularly beneficial to modern drug discovery programs. Herein, we report the development of redox-active difluoromethoxylating reagents for late-stage, direct difluoromethoxylation of unactivated arenes and heteroarenes through a radical-mediated mechanism under visible light photocatalytic conditions at room temperature (Scheme 1d). ${ }^{7-9}$

\section{Results and discussion}

A key to the success of the proposed transformation is the ability to generate and trap the $\mathrm{OCF}_{2} \mathrm{H}$ radical under mild reaction conditions. Although computational studies of the $\mathrm{OCF}_{2} \mathrm{H}$ radical have been reported, experimental access to such a radical intermediate remains rare. ${ }^{10}$ We envision that the ability to generate the $\mathrm{OCF}_{2} \mathrm{H}$ radical in a controllable, catalytic, and selective manner under mild conditions will open a new reaction platform for the preparation of an important class of difluoromethoxylated molecules. Our recent success in the development of trifluoromethoxylating reagents by taking advantage of the weak $\mathrm{N}-\mathrm{O}$ bond $\left(\Delta G_{\mathrm{N}-\mathrm{O}} \approx 57 \mathrm{kcal} \mathrm{mol}^{-1}\right)^{6,11}$ prompted us to question whether we could develop difluoromethoxylating reagents for the first photocatalytic formation and utilization of the $\mathrm{OCF}_{2} \mathrm{H}$ radical in organic synthesis. Thus, we synthesized and examined a series of benzotriazole-based $\mathrm{OCF}_{2} \mathrm{H}$ reagents $(\mathbf{1 a}, \mathbf{D R 1 - 5}$, Table 1 ) for direct aryl $\mathrm{C}-\mathrm{H}$ difluoromethoxylation of benzene. We found that cationic nature of the reagent is critical as it enhances the oxidizing power of the reagent and undergoes a photocatalytic single electron reduction to produce a neutral radical $\mathbf{1 a}^{\prime}$ that liberates the $\mathrm{OCF}_{2} \mathrm{H}$ radical selectively. Incorporation of electron
Table 1 Difluoromethoxylating reagent and reaction optimization ${ }^{a}$

(1a-DR5

${ }^{a}$ Reactions were performed using 1 equivalent of reagent and 10 equivalents of benzene. ${ }^{b}$ Yields were determined by ${ }^{19} \mathrm{~F}$ NMR spectroscopy using trifluorotoluene as an internal standard. ${ }^{c} 1$ equivalent of benzene. ${ }^{d}$ Without $\mathrm{Ru}(\mathrm{bpy})_{3}\left(\mathrm{PF}_{6}\right)_{2} \cdot{ }^{e}$ Without light. ${ }^{f}$ The reaction was set-up under air atomsphere.

deficient substituents on the benzotriazole ring prevents the addition of the $\mathrm{OCF}_{2} \mathrm{H}$ radical to the reagent byproducts and improves the reaction yields (entries 1, 3-6). Further reaction optimizations revealed that the reaction works with 1 equivalent of benzene albeit with diminished yield (40\%) accompanied with additional $24 \%$ of bis(difluoromethoxylated) side products (entry 7). Control experiments showed that photoredox catalysts and light are essential, but the oxygen free environment is not required (entries 8-10). It is noteworthy that reagent $\mathbf{1 a}(\mathrm{mp}=$ $153-154{ }^{\circ} \mathrm{C}$ ) be prepared in a multi-gram scale and is thermally stable beyond $200{ }^{\circ} \mathrm{C}$. Also, it can be manipulated and stored under ambient conditions without noticeable decomposition (see ESI $\dagger$ ).

With the redox-active cationic difluoromethoxylating reagent $\mathbf{1 a}^{12}$ and optimized photoredox-catalysed aryl $\mathrm{C}-\mathrm{H}$ difluoromethoxylation reaction conditions in hand, we then test the generality of the reaction against a wide array of arenes and heteroarenes. As shown in Table 2, a broad array of arenes and heteroarenes with diverse electronic properties and substitution patterns underwent photocatalytic (hetero)aryl $\mathrm{C}-\mathrm{H}$ difluoromethoxylation under optimized reaction conditions using reagent $\mathbf{1 a}$ at room temperature. The reaction tolerated halide substituents such as fluoride (3r), chloride (3b-3d), and bromide (3e, 3f, 3ab-3ad), which is important 
Table 2 Selected examples of difluoromethoxylation of (hetero)arenes ${ }^{a}$

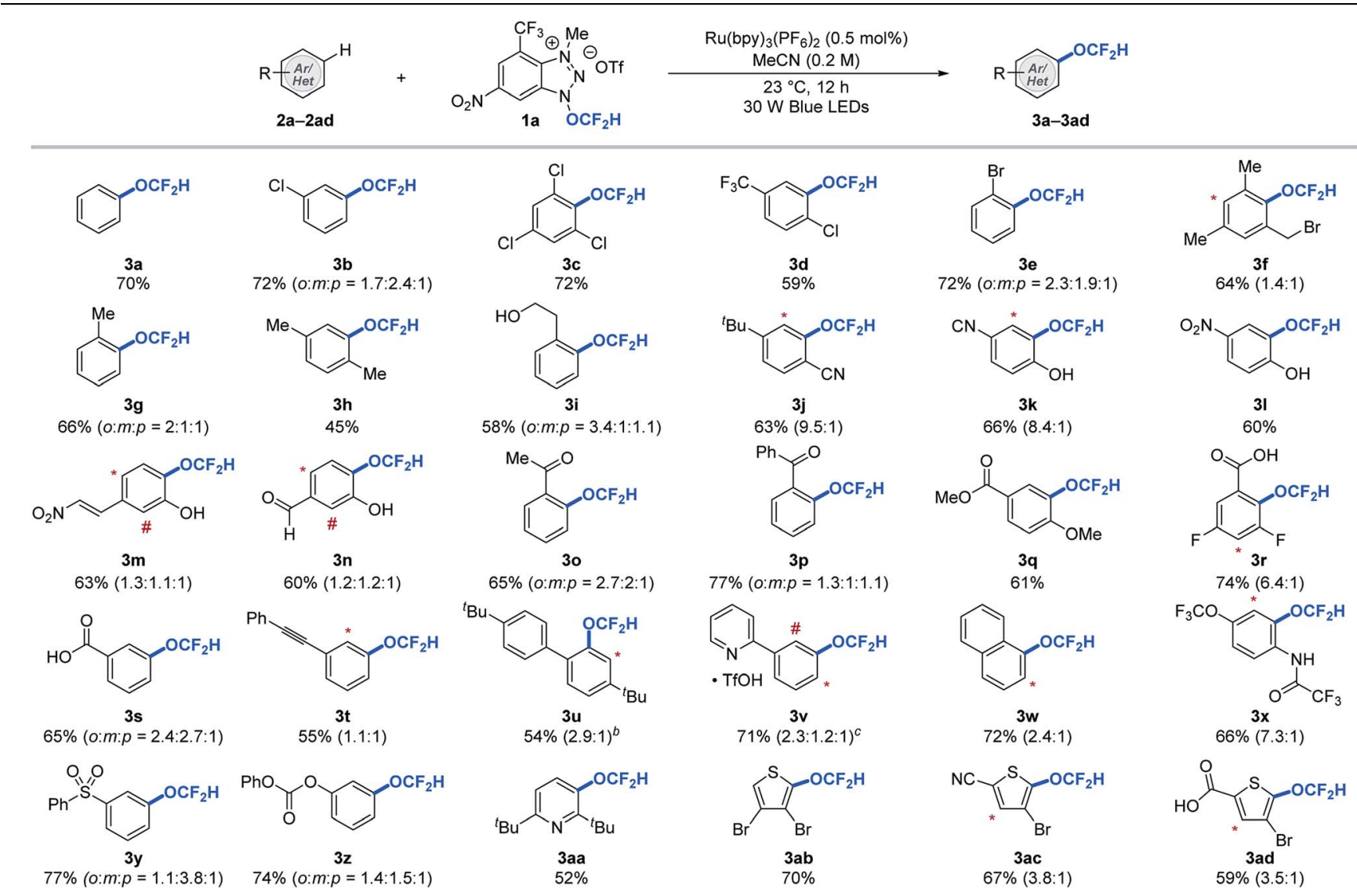

${ }^{a}$ Reactions were performed using 1.0 equivalent of reagent 1a and 10.0 equivalents of (hetero)arene. The asterisk $\left({ }^{*}\right)$ and number sign (\#) denote functionalization of minor regioisomeric products. Overall yields and the ratio of the constitutional isomers were determined by ${ }^{19} \mathrm{~F}$ NMR spectroscopy using trifluorotoluene as an internal standard. ${ }^{b}$ Reaction performed with $\mathrm{MeCN}$ and $\mathrm{CH}_{2} \mathrm{Cl}_{2}(1: 1,0.2 \mathrm{M}) .{ }^{c}$ Reaction performed with 10.0 equiv. of TfOH. See ESI for experimental details.

from a synthetic perspective since these substituents provide useful handles for further structural elaboration through metal-catalysed coupling reactions. The weak benzylic $\mathrm{C}-\mathrm{H}$ bond (BDE $\left.\approx 88 \mathrm{kcal} \mathrm{mol}^{-1}, \mathbf{3 f}-3 \mathbf{i}\right),{ }^{13}$ which is often a site for undesired reactivity in radical processes, proved compatible. More remarkably, unprotected alcohols (3i) and phenols (3k3n) remained intact during the reaction. Carbonyl derivatives such as aldehydes (3n), ketones with or without enolizable protons (3o, 3p), carboxylic acids (3r, 3s, 3ad), esters (3q), amides (3x), and carbonates (3z) reacted smoothly to afford the desired products in good yields. Other functional groups such as trifluoromethyl (3d), methoxy (3q), trifluoromethoxy (3x), cyano $(3 \mathbf{j}, 3 \mathbf{k}, \mathbf{3 a c})$, nitro $(\mathbf{3} \mathbf{l}, \mathbf{3 m})$, sulfonyl $(3 \mathbf{y})$, and pyridinium (3v) were all well tolerated under the reaction conditions. Moreover, no competing radical addition to electron deficient olefin (3m) or alkyne (3t) was observed during the aryl difluoromethoxylation reaction. Heteroarenes such as pyridine (3aa) and thiophene (3ab-3ad) derivatives were also viable substrates. The reaction proceeded with one equivalent of arenes, but higher yields were obtained using ten equivalents of arenes. ${ }^{12}$ In such cases, we could recover 8.3-9.1 equivalents (see ESI $\dagger$ ) of the aromatic substrates at the end of the reaction, which is critical for valuable aromatic compounds.

Late-stage modifications of biologically active molecules are often a key to identification of medicinal agents. ${ }^{14}$ To demonstrate the amenability of the photocatalytic difluoromethoxylation processes to late-stage synthetic applications, biorelevant molecules were subjected to our standard reaction conditions using arenes as limiting reactants (Table 3). Approved drug molecules such as Baclofen ${ }^{\circledR}$ (muscle relaxant), Febuxostat ${ }^{\circledR} \quad$ (anti-hyperuricemic), Mexiletine ${ }^{\circledR}$ (antiarrhythmic), Efavirenz® (antiretroviral drug for treating HIV), as well as Metronidazole ${ }^{\circledR}$ (antiparasitic) and L-menthol (decongestants and analgesics) analogues were successfully difluoromethoxylated using reagent 1a to afford the desired products (5a-5f) in synthetically useful $42-76 \%$ yields, based on the recovery of the starting materials (BRSM). Our difluoromethoxylation strategy is applicable to a range of drug molecules and tolerates a number of sensitive functionalities, and this shows its potential utility in modern drug discovery programs. 
Table 3 Selected examples of difluoromethoxylation of biorelevant molecules $^{a}$

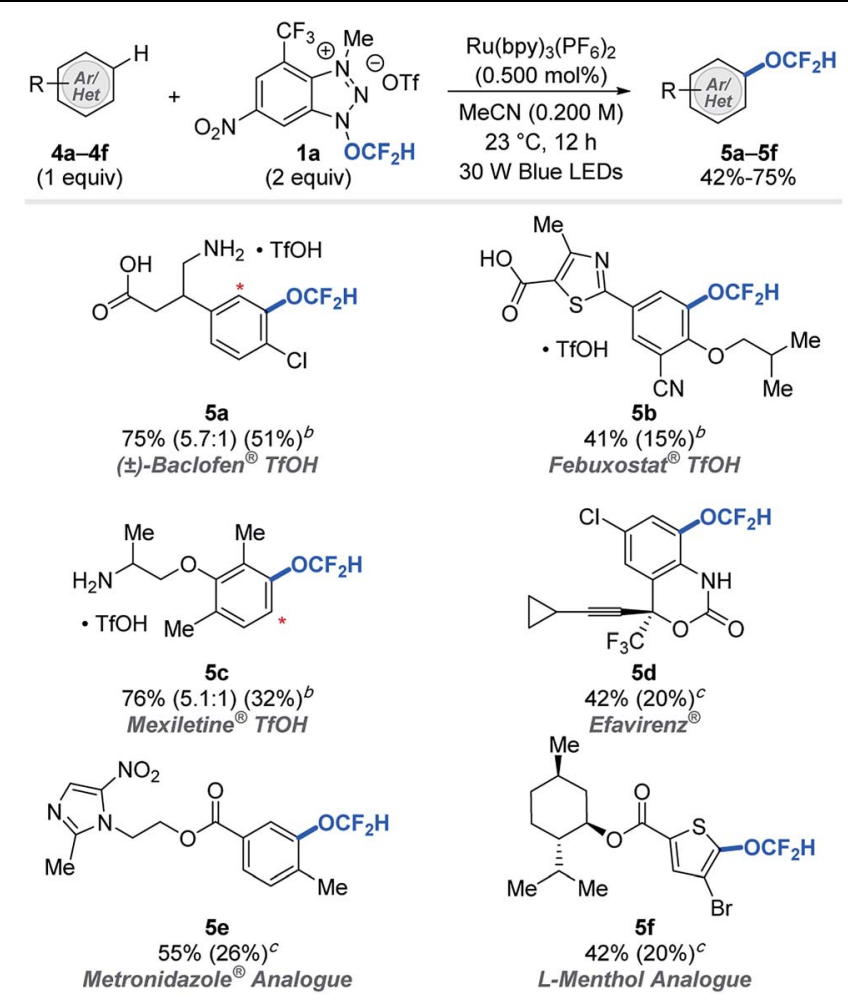

${ }^{a}$ Yields were determined based on the recovered starting material. The yield in parentheses is the isolated yield. The asterisk $(*)$ denotes functionalization of a minor regioisomeric product. ${ }^{b}$ Reaction performed with 1.00 equivalent of TfOH. ${ }^{c} 1.00$ equivalent of $\mathrm{K}_{2} \mathrm{CO}_{3}$. See ESI for experimental details.

Our approach capable of forming multiple regioisomers in a single synthetic operation is complementary to the conventional site-selective protocols using phenols as substrates and could be useful in discovery chemistry. The regioselectivity of the reaction resembles that of radical-mediated aromatic substitution processes and is guided by the electronics of the substituent except in the case of a bulky substituent such as $\mathbf{3 j}$, in which case the $\mathrm{OCF}_{2} \mathrm{H}$ radical adds preferably to the position distal from the tert-butyl group. If an aromatic substrate has multiple reaction sites, the $\mathrm{OCF}_{2} \mathrm{H}$ radical will add to these sites to form regioisomeric products, which could be separated to provide pure isomers (see ESI $\dagger$ ). Such reactivity is particularly attractive from a drug discovery point of view because it allows rapid access to various $\mathrm{OCF}_{2} \mathrm{H}$ derivatives without labourintensive, parallel multi-step analogue synthesis. ${ }^{\mathbf{1 4 , 1 5}}$ More importantly, it will increase the efficiency of structure-activity relationship (SAR) studies of $\mathrm{OCF}_{2} \mathrm{H}$ analogues and can conveniently produce promising new candidates that might have never been evaluated otherwise.

We then performed a series of experiments and DFT calculations to better understand the reactivity of the $\mathrm{OCF}_{2} \mathrm{H}$ radical and the reaction mechanism (Scheme 2). The quantum yield of the reaction is 0.52 , which supports that an extended radical chain mechanism is unlikely. This observation corroborates DFT

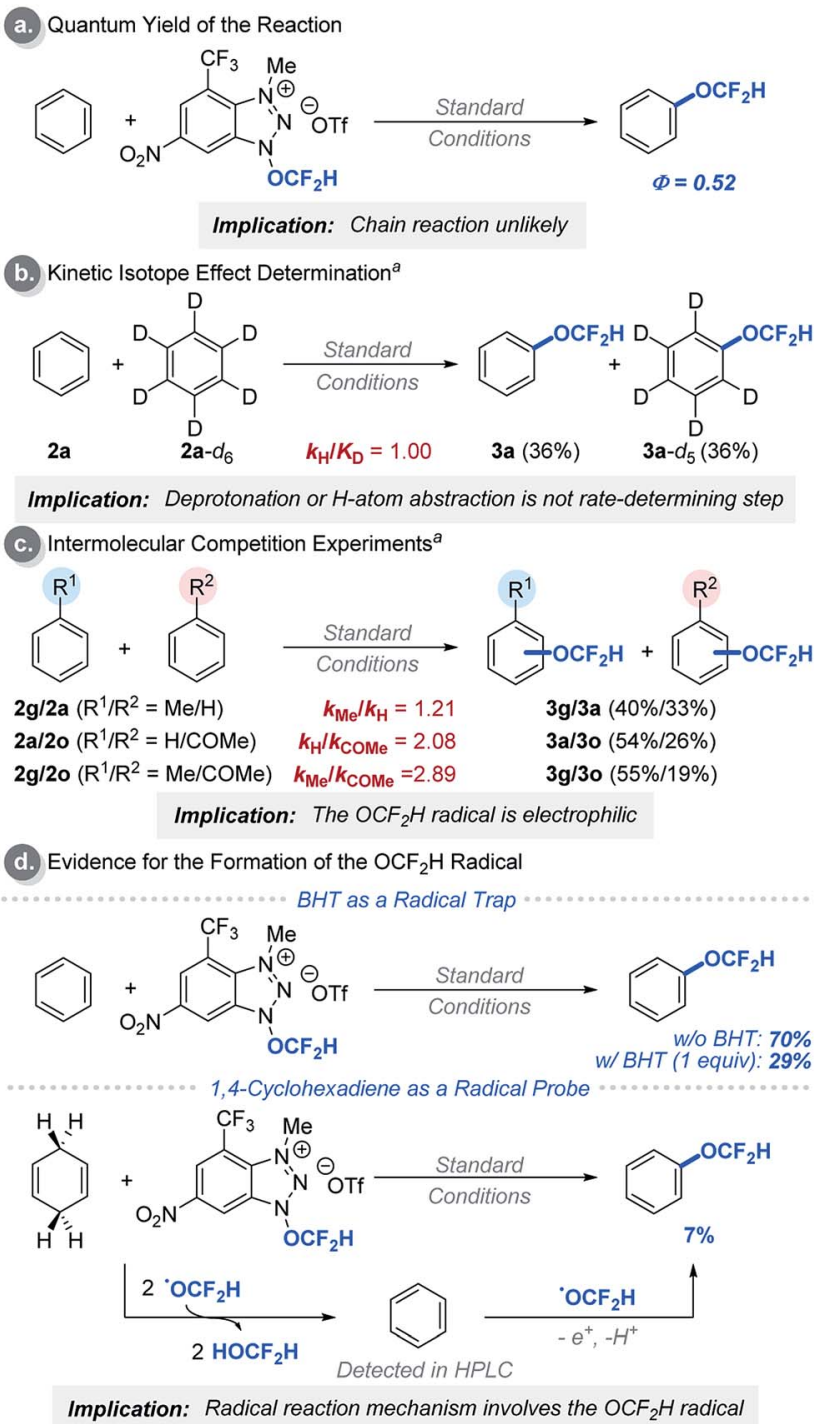

Scheme 2 Experimental mechanism studies: ${ }^{a}$ reactions were performed using 5.00 equivalents of arenes each. See ESI† for experimental details.

calculations (see Fig. S24 $\dagger$ ). A series of Stern-Volmer quenching studies showed that only $\mathbf{1 a}$ quenched the excited ${ }^{*} \mathrm{Ru}(\mathrm{bpy})_{3}{ }^{2+}$ efficiently $\left(k_{\mathrm{q}}=2.08 \times 10^{9} \mathrm{M}^{-1} \mathrm{~s}^{-1}\right)$ (Fig. S8 $\dagger$ ). To further probe the reaction mechanism, kinetic isotope effect (KIE) experiments were conducted using a $1: 1$ mixture of benzene and $d_{6}$-benzene in the presence of reagent 1a, affording the desired products $\mathrm{Ph}$ $\mathrm{OCF}_{2} \mathrm{H}$ and $d_{5}-\mathrm{Ph}-\mathrm{OCF}_{2} \mathrm{H}$ in a $1: 1$ ratio (Scheme $2 \mathrm{~b}$ ). This result excludes the possibility of $\mathrm{H}$-atom abstraction/deprotonation as the rate-determining step. Moreover, intermolecular competition experiments using two electronically diverse arenes revealed that the $\mathrm{OCF}_{2} \mathrm{H}$ radical reacts more favourably with electron-rich arenes, and this confirms its electrophilic character (Scheme 2c). The formation of the $\mathrm{OCF}_{2} \mathrm{H}$ radical is the key for the success of the (hetero)aryl $\mathrm{C}-\mathrm{H}$ difluoromethoxylation and is supported by (i) the regioselectivity of the reaction, and (ii) radical trap experiments using butylated hydroxytoluene (BHT) and 1,4cyclohexadiene (Scheme 2d). Addition of 1 equivalent of BHT to 
Energies of Catalytic \& Selective Formation of the $\mathrm{OCF}_{2} \mathrm{H}$ Radical ${ }^{\mathrm{a}}$
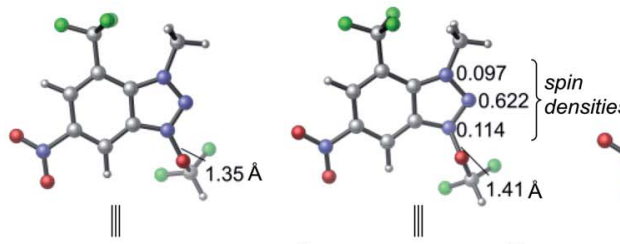

||

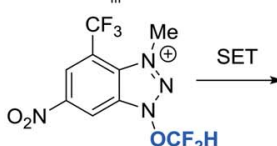

$1 \mathrm{a}$
+

${ }^{*} \mathrm{Ru}(\mathrm{bpy})_{3}{ }^{2+}$

$\Delta G=0 \mathrm{kcal} \mathrm{mol}^{-1}$

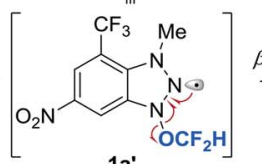

$1 a^{\prime}$

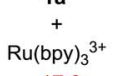

$-17.0$

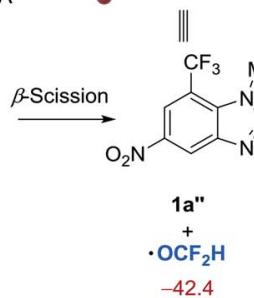

b. Proposed Mechanism
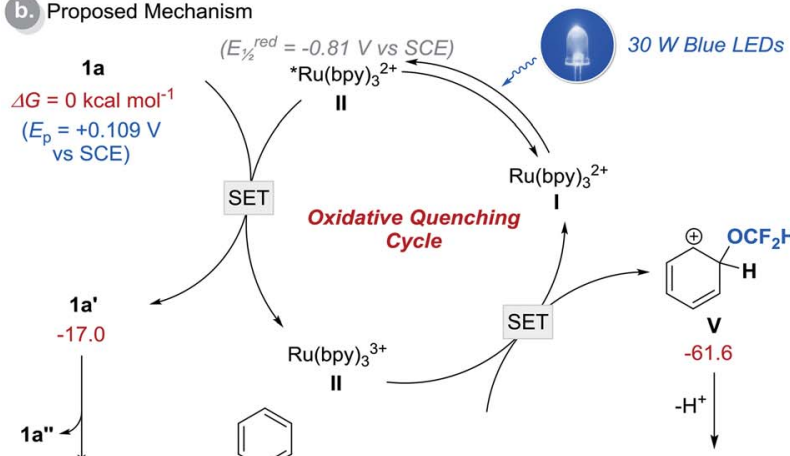

$\checkmark$
. $\mathrm{OCF}_{2} \mathrm{H}$
-42.4

Disfavoured

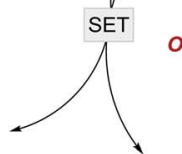

Oxidative Quenching I

Cycle

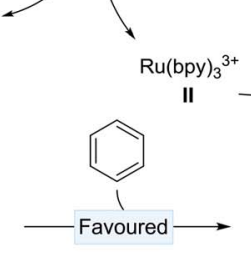

$\mathrm{OCF}_{2}+\mathrm{H}^{\cdot}-36.5$
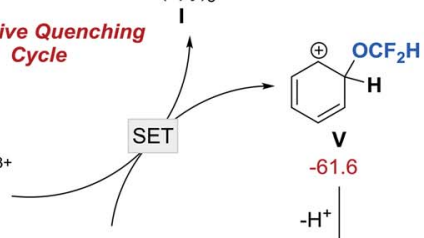

$\mathbf{V}$
-61.6

$-\mathrm{H}^{+}$

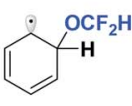

IV

$-44.9$

Scheme 3 Computational studies and proposed reaction mechanism. ${ }^{a}$ DFT calculations were performed at the M06-2X/6-311++G(d,p)/ $\mathrm{SMD}(\mathrm{MeCN}) / / \mathrm{M06}-2 \mathrm{X} / 6-31+\mathrm{G}(\mathrm{d})$ level of theory using reagent $1 \mathrm{a}$ and benzene as a substrate. All energies are in $\mathrm{kcal} \mathrm{mol}^{-1}$ and are with respect to II and 1 a. See (ESI†) for details.

the reaction mixture lowered the product yield from $70 \%$ to $29 \%$. When 1,4-cyclohexadiene was used as a substrate, we observed the formation of the desired product $3 \mathbf{a}$ in $7 \%$ yield. Presumably, once the $\mathrm{OCF}_{2} \mathrm{H}$ radical is formed, it undergoes two consecutive $\mathrm{H}$-atom abstraction from 1,4-cyclohexadiene, generating benzene as the product. Subsequently, this benzene can react with the $\mathrm{OCF}_{2} \mathrm{H}$ radical under photocatalytic conditions, furnishing the difluoromethoxylated product. A key feature of our cationic redox-active reagent $\mathbf{1 a}$ is its susceptibility to single electron reduction to form a neutral radical $\left(\mathbf{1 a}^{\prime}\right)$ that undergoes $\beta$-scission liberating the $\mathrm{OCF}_{2} \mathrm{H}$ radical exclusively (Scheme 3a). DFT calculations showed that both steps are energetically favourable in the presence of an excited photoredox catalyst, ${ }^{*} \mathrm{Ru}(\mathrm{bpy})_{3}{ }^{2+}$. Once the $\mathrm{OCF}_{2} \mathrm{H}$ radical is formed, the subsequent steps (i.e., the addition of the $\mathrm{OCF}_{2} \mathrm{H}$ radical to an arene, oxidation of the resulting cyclohexadienyl radical by $\mathrm{Ru}(\mathrm{bpy})_{3}{ }^{3+}$, and deprotonation) are all exergonic (Fig. $\mathrm{S} 24 \dagger$ ). We have determined the peak potential of reagent $1 \mathrm{a}\left[E_{\mathrm{p}}\left(\mathbf{1 a}^{+} / \mathbf{1 a}\right)=+0.109 \mathrm{~V}\right.$ versus saturated calomel electrode (SCE) in MeCN, Fig. S6†], and so it can be reduced by the excited ${ }^{*} \mathrm{Ru}(\mathrm{bpy})_{3}{ }^{2+}\left(E_{1 / 2}^{\mathrm{red}}=-0.81 \mathrm{~V}\right.$ versus $\mathrm{SCE}$ in $\mathrm{MeCN}) \cdot{ }^{16}$
Based on these preliminary results, a catalytic cycle of this transformation was hypothesized and depicted in Scheme $3 \mathrm{~b}$. Initial excitation of the $\mathrm{Ru}(\mathrm{bpy})_{3}{ }^{2+}$ photocatalyst (I, bpy $=2,2^{\prime}-$ bipyridine) produces the long-lived triplet-excited state of ${ }^{*} \mathrm{Ru}(\mathrm{bpy})_{3}{ }^{2+}\left(\mathrm{II}, t_{1 / 2}=1.1 \mu \mathrm{s}\right) .{ }^{17}$ This catalyst $(\mathrm{II})\left(E_{1 / 2}^{\mathrm{red}}=-0.81 \mathrm{~V}\right.$ versus SCE in $\mathrm{MeCN})^{\mathbf{1 6}}$ undergoes SET with the redox-active cationic reagent $1 \mathrm{a}\left(E_{\mathrm{p}}\right.$ of $1 \mathrm{a}=+0.109 \mathrm{~V}$ versus $\mathrm{SCE}$ in MeCN) generating $\mathrm{Ru}(\mathrm{bpy})_{3}{ }^{3+}$ and neutral radical $\mathbf{1 a}^{\prime}$ that undergoes $\beta$ scission to liberate benzotriazole $\left(\mathbf{1 a}^{\prime \prime}\right)$ and the $\mathrm{OCF}_{2} \mathrm{H}$ radical. The addition of this radical to an arene to form cyclohexadienyl radical IV is thermodynamically more favourable than the decomposition of the $\mathrm{OCF}_{2} \mathrm{H}$ radical to fluorophosgene and hydrogen atom. ${ }^{\mathbf{1 0 b}}$ Oxidation of IV by $\mathrm{Ru}(\mathrm{bpy})_{3}{ }^{3+}\left(E_{1 / 2}^{\mathrm{red}}=+1.28 \mathrm{~V}\right.$, versus $\mathrm{SCE}$ in MeCN) affords cyclohexadienyl cation $\mathbf{V}$, which is deprotonated to give the desired $\mathrm{C}-\mathrm{H}$ difluoromethoxylated arenes.

\section{Conclusions}

In summary, we have developed a redox-active cationic reagent 1a and identified photocatalytic conditions that allow facile difluoromethoxylation of arenes and heteroarenes without the need for aryl ring pre-functionalization or pre-activation. This radical-based aromatic substitution process provides rapid access to multiple regioisomers in a single synthetic operation, which will facilitate molecular screening and SAR studies of $\mathrm{OCF}_{2} \mathrm{H}$ analogues. The synthetic utility of our strategy has been highlighted by the late-stage difluoromethoxylation of biorelevant molecules at ambient temperature and pressure. Notably, this report not only provides the first experimental access to and utilization of the $\mathrm{OCF}_{2} \mathrm{H}$ radical but also establishes the first photocatalytic and selective formation of the $\mathrm{OCF}_{2} \mathrm{H}$ radical. We expect that this reagent and protocol will create a new avenue for the design and development of difluoromethoxylation reactions of hydrocarbons to aid the discovery and synthesis of new pharmaceuticals.

\section{Conflicts of interest}

The authors declare no conflict of interest.

\section{Acknowledgements}

Financial support for this work was provided by $\mathrm{NIH}$ (R35GM119652 to M.-Y. N.), the NSF (CHE-1654122 to P. L.), and National Science Foundation Graduate Research Fellowship Program under Grant No. 1747452. We thanks Peng Zhao for help with measurement of the emission spectrum of the LED light and Zhixiu Liang for the CV measurements. Calculations were performed at the Center for Research Computing at the University of Pittsburgh and the Extreme Science and Engineering Discovery Environment (XSEDE) supported by the NSF (ACI-1053575).

\section{Notes and references}

1 (a) S. Purser, P. R. Moore, S. Swallow and V. Gouverneur, Chem. Soc. Rev., 2008, 37, 320-330; (b) I. Ojima, Fluorine in 
Medicinal Chemistry and Chemical Biology, Blackwell Publishing Ltd, 2009; (c) T. Liang, C. N. Neumann and T. Ritter, Angew. Chem., Int. Ed., 2013, 52, 8214-8264; (d) J. Wang, M. Sánchez-Roselló, J. L. Aceña, C. del Pozo, A. E. Sorochinsky, S. Fustero, V. A. Soloshonok and H. Liu, Chem. Rev., 2014, 114, 2432-2506; (e) W. Zhu, J. Wang, S. Wang, Z. Gu, J. L. Aceña, K. Izawa, H. Liu and V. A. Soloshonok, J. Fluorine Chem., 2014, 167, 37-54; (f) Y. Zhou, J. Wang, Z. Gu, S. Wang, W. Zhu, J. L. Aceña, V. A. Soloshonok, K. Izawa and H. Liu, Chem. Rev., 2016, 116, 422-518.

2 (a) K. Müller, Chimia, 2014, 68, 356-362; (b) Q. A. Huchet, N. Trapp, B. Kuhn, B. Wagner, H. Fischer, N. A. Kratochwil, E. M. Carreira and K. Müller, J. Fluorine Chem., 2017, 198, 34-46.

3 (a) K. Müller, C. Faeh and F. Diederich, Science, 2007, 317, 1881-1886; (b) L. Xing, D. C. Blakemore, A. Narayanan, R. Unwalla, F. Lovering, R. A. Denny, H. Zhou and M. E. Bunnage, ChemMedChem, 2015, 10, 715-726.

4 S. M. Cheer, A. Prakash, D. Faulds and H. M. Lamb, Drugs, 2003, 63, 101-133.

5 Synthesis of aryl difluoromethyl ethers from phenols. For a review on using carbene intermediate, see: $(a) \mathrm{C}$. Ni and J. Hu, Synthesis, 2014, 46, 842-863; for selected examples of stoichiometric reactions, see: (b) L. Zhang, J. Zheng and J. Hu, J. Org. Chem., 2006, 71, 9845-9848; (c) J. Zheng, Y. Li, L. Zhang, J. Hu, G. J. Meuzelaar and H.-J. Federsel, Chem. Commun., 2007, 5149-5151; (d) Y. Zafrani, G. Sod-Moriah and Y. Segall, Tetrahedron, 2009, 65, 5278-5283; (e) F. Wang, W. Huang and J. Hu, Chin. J. Chem., 2011, 29, 2717-2721; (f) F. Wang, L. Zhang, J. Zheng and J. Hu, J. Fluorine Chem., 2011, 132, 521-528; $(g)$ J. B. Sperry and K. Sutherland, Org. Process Res. Dev., 2011, 15, 721-725; (h) P. S. Fier and J. F. Hartwig, Angew. Chem., Int. Ed., 2013, 52, 2092-2095; ( $i$ ) C. S. Thomoson and W. R. Dolbier Jr, J. Org. Chem., 2013, 78, 8904-8908; (j) L. Li, F. Wang, C. Ni and J. Hu, Angew. Chem., Int. Ed., 2013, 52, 12390-12394; for examples of catalytic $\mathrm{O}-\mathrm{CF}_{2} \mathrm{H}$ bond forming reactions, see: (k) K. Levchenko, O. P. Datsenko, O. Serhiichuk, A. Tolmachev, V. O. Iaroshenko and P. K. Mykhailiuk, J. Org. Chem., 2016, 81, 5803-5813; (l) J. Yang, M. Jiang, Y. Jin, H. Yang and H. Fu, Org. Lett., 2017, 19, 2758-2761. For examples of other indirect, multi-step strategies, see: (m) Y. Hagooly, O. Cohen and S. Rozen, Tetrahedron Lett., 2009, 50, 392-394; (n) W. R. Dolbier Jr, F. Wang, X. Tang, C. S. Thomoson and L. Wang, J. Fluorine Chem., 2014, 160, 72-76.

6 (a) J. W. Lee, D. N. Spiegowski and M. Y. Ngai, Chem. Sci., 2017, 8, 6066-6070; (b) W. Zheng, C. A. Morales-Rivera, J. W. Lee, P. Liu and M. Y. Ngai, Angew. Chem., Int. Ed.,
2018, 57, 9645-9649; (c) W. Zheng, J. W. Lee, C. A. MoralesRivera, P. Liu and M. Y. Ngai, Angew. Chem., Int. Ed., 2018, 57, 13795-13799.

7 Selected reviews on photoredox catalysis: (a) C. K. Prier, D. A. Rankic and D. W. C. MacMillan, Chem. Rev., 2013, 113, 5322-5363; (b) M. D. Karkas, J. A. Porco Jr and C. R. Stephenson, Chem. Rev., 2016, 116, 9683-9747; (c) N. A. Romero and D. A. Nicewicz, Chem. Rev., 2016, 116, 10075-10166; (d) K. L. Skubi, T. R. Blum and T. P. Yoon, Chem. Rev., 2016, 116, 10035-10074; (e) J. K. Matsui, S. B. Lang, D. R. Heitz and G. A. Molander, ACS Catal., 2017, 7, 2563-2575.

8 Reviews on photocatalytic formation of alkoxy radicals: $(a)$ J. Zhang and Y. Y. Chen, Acta Chim. Sin., 2017, 75, 41-48; (b) J. J. Guo, A. H. Hu and Z. W. Zuo, Tetrahedron Lett., 2018, 59, 2103-2111; (c) K. F. Jia and Y. Y. Chen, Chem. Commun., 2018, 54, 6105-6112.

9 Selected examples of photocatalytic formation of alkoxy radicals via N-O bond cleavage: (a) V. Quint, F. MorletSavary, J. F. Lohier, J. Lalevee, A. C. Gaumont and S. Lakhdar, J. Am. Chem. Soc., 2016, 138, 7436-7441; (b) C. Y. Wang, K. Harms and E. Meggers, Angew. Chem., Int. Ed., 2016, 55, 13495-13498; (c) J. Zhang, Y. Li, F. Y. Zhang, C. C. Hu and Y. Y. Chen, Angew. Chem., Int. Ed., 2016, 55, 1872-1875; (d) J. Zhang, Y. Li, R. Y. Xu and Y. Y. Chen, Angew. Chem., Int. Ed., 2017, 56, 12619-12623; (e) B. J. Jelier, P. F. Tripet, E. Pietrasiak, I. Franzoni, G. Jeschke and A. Togni, Angew. Chem., Int. Ed., 2018, 57, 13784-13789; $(f)$ A.-L. Barthelemy, B. Tuccio, E. Magnier and G. Dagousset, Angew. Chem., Int. Ed., 2018, 57, 1379013794.

10 Computation studies of the $\mathrm{OCF}_{2} \mathrm{H}$ radical, see: (a) J. Rayez, M. Rayez, P. Halvick, B. Duguay and J. Dannenberg, Chem. Phys., 1987, 118, 265-272; (b) J. Francisco and Y. Zhao, J. Chem. Phys., 1990, 93, 276-286; (c) W. F. Schneider, B. I. Nance and T. J. Wallington, J. Am. Chem. Soc., 1995, 117, 478-485.

11 A. A. Tabolin and S. L. Ioffe, Chem. Rev., 2014, 114, 54265476.

12 See ESI $\dagger$ for detailed optimization tables.

13 G. B. Ellison, G. E. Davico, V. M. Bierbaum and C. H. DePuy, Int. J. Mass Spectrom. Ion Processes, 1996, 156, 109-131.

14 T. Cernak, K. D. Dykstra, S. Tyagarajan, P. Vachal and S. W. Krska, Chem. Soc. Rev., 2016, 45, 546-576.

15 D. A. Nagib and D. W. MacMillan, Nature, 2011, 480, 224228.

16 C. Bock, T. Meyer and D. Whitten, J. Am. Chem. Soc., 1975, 97, 2909-2911.

17 A. Juris, V. Balzani, P. Belser and A. von Zelewsky, Helv. Chim. Acta, 1981, 64, 2175-2182. 